\title{
Fragmented QRS is a marker of mortality in patients with severe COVID-19: A retrospective observational study
}

\author{
İbrahim Halil Özdemir1, 2 (D), Bülent Özlek (), Mehmet Burak Özen1, 2 (D), Ramazan Gündüz1, 2 (D), \\ Nurullah Çetin ${ }^{4}$ (D), Eda Özlek ${ }^{3}$, Bekir Serhat Yıldız ${ }^{4}$ (D), Hakan Tıkız ${ }^{4}$ (D) \\ ${ }^{1}$ Department of Cardiology, Manisa City Hospital; Manisa-Turkey \\ ${ }^{2}$ Department of Cardiology, Merkez Efendi State Hospital; Manisa-Turkey \\ ${ }^{3}$ Department of Cardiology, Faculty of Medicine, Sttkı Koçman University; Muğla-Turkey \\ ${ }^{4}$ Department of Cardiology, Faculty of Medicine, Celal Bayar University; Manisa-Turkey
}

ABSTRACT

Objective: In this study, we aimed to investigate the association of fragmented QRS (f-QRS) with in-hospital death in patients with severe novel coronavirus disease 2019 (COVID-19).

Methods: This was a retrospective and observational study. A total of 201 consecutive patients with severe COVID-19 were enrolled. Demographic data, laboratory parameters, medications, electrocardiographic (ECG) findings, and clinical outcomes were recorded. Patients with and without $\mathrm{f}$-QRS were compared, and predictors of all-cause in-hospital mortality were analyzed.

Results: A total of 135 patients without f-QRS (mean age of 64 years, $43 \%$ women) and 66 patients with f-0RS (mean age of 66 years, $39 \%$ women) were included. C-reactive protein (CRP), D-dimer, troponin I, ferritin levels, and CRP to albumin ratio were significantly higher in patients with $\mathrm{f}$-QRS. The need for invasive mechanical ventilation (63.6\% vs. $41.5 \%, \mathrm{p}=0.003)$ and all-cause in-hospital mortality [ $54.5 \%$ vs. $28.9 \%$, log rank $p=0.001$, relative risk $1.88,95 \%$ confidence interval $(\mathrm{Cl}) 1.16-4.78$ ] were significantly higher in patients with $\mathrm{f}$-QRS. A number value of $\mathrm{f}-\mathrm{QRS}$ leads $\geq 2$ yields sensitivity and specificity ( $85.3 \%$ and $86.7 \%$, respectively) for predicting in-hospital all-cause mortality. Multivariable analysis showed that f-QRS (odds ratio: $1.041,95 \% \mathrm{Cl}: 1.021-1.192, \mathrm{p}=0.040$ ) were independently associated with in-hospital death.

Conclusion: This study revealed that the presence of $\mathrm{f}-\mathrm{QRS}$ in ECG is associated with higher in-hospital all-cause mortality in patients with severe COVID-19. f-ORS is an easily applicable simple indicator to predict the risk of death in these patients.

Keywords: coronavirus disease 2019, electrocardiography, fragmented ORS, mortality

Cite this article as: Özdemir IH, Özlek B, Özen MB, Gündüz $R$, Çetin N, Özlek E, et al. Fragmented QRS is a marker of mortality in patients with severe COVID-19: A retrospective observational study. Anatol J Cardiol 2021; 25: 811-20.

\section{Introduction}

In December 2019, the Chinese city of Wuhan drew attention with cases of pneumonia of unknown origin. When the cause of pneumonia was investigated, a virus (which was later called 2019 novel coronavirus) was found (1). The World Health Organization (WHO) announced a standard format of coronavirus disease 2019 (COVID-19) for this novel coronavirus pneumonia on February 11, 2020; and on the same day, the International Committee on Taxonomy of Viruses named this novel coronavirus, severe acute respiratory syndrome coronavirus 2 (SARSCoV-2) (2). Given the rapid spread of this virus, COVID-19 was declared a pandemic by the WHO on March 11, 2020 (3).
Mortality owing to COVID-19 is generally caused by the respiratory system. Complications arising from the cardiovascular system are another important cause of mortality. Cardiac complications due to COVID-19 may be because of myocardial injury (mainly owing to ischemia or myocarditis), arrhythmia, new onset, or worsening of pre-existing heart failure, thromboembolic events, and medical therapy (4).

In a study evaluating the electrocardiography (ECG) data of patients with COVID-19, it is recommended that patients with delayed ventricular conduction should be monitored more closely (5). Fragmented QRS ( $f-Q R S$ ) is a relatively new parameter of proven prognostic value in various populations. Its presence on ECG is associated with myocardial scarring and ven-

Address for Correspondence: Dr. İbrahim Halil Özdemir, Manisa Şehir Hastanesi, Kardiyoloji Kliniği, Manisa-Türkiye

Phone: +90 5320581236 E-mail: dr.ibrahimhalilozdemir@gmail.com

Accepted Date: 05.05.2021 Available Online Date: 20.10.2021

(C) Copyright 2021 by Turkish Society of Cardiology - Available online at www.anatoljcardiol.com DOl:10.5152/AnatolJCardiol.2021.62 


\section{HIGHLIGHTS}

- Fragmented QRS ( $\mathrm{f}-\mathrm{QRS}$ ) is a marker that shows myocardial scar and can be easily determined by electrocardiography (ECG).

- The presence of $\mathrm{f}-\mathrm{QRS}$ on ECG is independently associated with all-cause in-hospital mortality in patients with severe coronavirus disease 2019 (COVID-19).

- The need for invasive mechanical ventilation was higher in critically ill patients with COVID-19 and f-ORS.

- There is a positive correlation between the presence of $\mathrm{f}-\mathrm{QRS}$ with C-reactive protein (CRP) and CRP to albumin ratio.

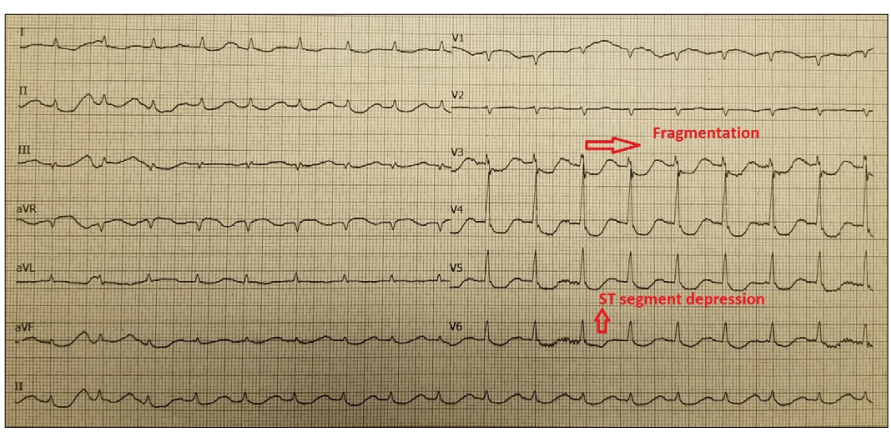

Figure 1. ECG sample with fragmented QRS and ST segment depression

tricular conduction disturbances, which may predispose a patients to ventricular arrhythmias (6-9). f-ORS can be defined as the presence of additional $R^{\prime}$ waves or a notch in the nadir of the $\mathrm{R}$ or $\mathrm{S}$ wave (fragmentation) in 2 contiguous leads corresponding to a coronary territory in a routine 12-lead ECG (0.5$150 \mathrm{~Hz}$ ) (Fig. 1) (10). The f-ORS is an easily detectable parameter in the standard 12-lead ECG and has been associated with mortality in many cardiovascular events (11).

The number of studies investigating the association between the presence of f-QRS and clinical outcomes in severe COVID-19 is limited. Therefore, we aimed to assess the relationship between $\mathrm{f}-\mathrm{QRS}$ and in-hospital mortality in patients critically ill with COVID-19.

\section{Methods}

The study was designed retrospectively at Merkez Efendi State Hospital, which is a pandemic hospital in Manisa City of Turkey. The Ministry of Health, Republic of Turkey, gave approval for the study. The research protocol complied with the Declaration of Helsinki and was approved by Celal Bayar University Medicine Faculty, Non-Interventional Clinical Trials Ethics Committee (decision \#85252386-050.04.04.04). Consecutive 201 patients with severe COVID-19 followed from June 01 to September 30, 2020, in the intensive care unit (ICU) were included in this study. Patients who did not require follow-up in the ICU were not included in the study. A total of 218 hospitalized patients in the ICU with the diagnosis of COVID-19 were examined retrospectively. Four patients with DDD-pacemaker and 1 patient with VVI-pacemaker were excluded from the study, and 12 patients were excluded from the study because electrocardiographic data were not available. In the final analysis, 201 patients were included in the study. SARS-CoV-2 PCR tests (SARS-CoV-2 with qPCR Detection Kit and Bio-Speedy) were positive for all the patients. The ECGs were obtained and evaluated on admission to the ICU. The patients were divided into 2 groups as patients with fragmented and non-fragmented ORS. The ECG recording device was MAC 2000, GE Medical Systems Information Technologies, Inc., Milwaukee, Wisconsin, USA. The ECG data of all the patients were extracted from the hospital archive and electronic medical records. All demographic characteristics (age and sex), symptoms, pre-existing comorbidities, laboratory parameters, drugs, and outcome data were recorded by investigating the medical history of the patients. Chest computed tomography (CT) findings of all the patients were categorized according to radiology reports. Patients who needed mechanical ventilation owing to respiratory failure were recorded. The all-cause in-hospital mortality of the patients was recorded. We followed all the patients during their hospital stay. Fifty patients were randomly selected to repeat the analysis of the QRS complex, this time blinded, by the same operator and by a second operator to establish the interobserver and intraobserver variability.

\section{Statistical analysis}

In this study, which was conducted to determine the association between $\mathrm{f}-\mathrm{QRS}$ complex and disease severity in patients with COVID-19, power was determined by taking at least 0.80 and $1^{\text {st }}$ type error as 0.05 for each variable. The categorical variables were expressed in frequencies and percentages. Categorical variables were compared using the $\chi^{2}$ test. Baseline continuous variables were presented as mean \pm standard deviations (SD) or median (interquartile range), depending on the distribution of the data. Whether the continuous measurement averages were normally distributed or not was checked with the Kolmogorov-Smirnov $(n>50)$ and Skewness-Kurtosis tests, and parametric tests were applied because the variables were normally distributed. The continuous variables were compared using the t-test or the Mann-Whitney $\mathrm{U}$ test as appropriate. Independent t-test was performed to compare the measurement averages according to the f-QRS factor. Survival analysis (Kaplan-Meier method) and log-rank test were used to determine the effects of some factors on survival rates. f-ORS cut-off values to predict mortality were determined by the area under the curve (AUC) and receiver operating characteristic (ROC) analysis. Spearman correlation co-efficients were calculated to determine relationships between measurements. To determine interobserver and intraobserver variability, we used the intraclass correlation coefficient (ICC) for continuous variables and the kappa coefficient for categorical variables. An ICC $<0.4$ was considered poor, ICC of 0.4-0.75 fair to good; ICC $>0.75$ excellent. Binary logistic regression analysis was applied to identify 
predictors of in-hospital mortality. For all analyses, $p<0.05$ was considered statistically significant. Analyses are performed with the Statistical Package for the Social Sciences version 24.0 (SPSS Inc, Chicago, Illinois, USA).

\section{Results}

A total of 201 consecutive patients critically ill with COVID-19 were included in this study. The number of patients with f-QRS was 66 , and the number of patients without it was 135 . Baseline characteristics of study population are given in Table 1. The mean age of all population was 65 years. There were no significant differences in age, sex, smoking, alcohol use, body mass index, or blood pressure between the two groups. Prevalence of the symptoms on admission such as fever, cough, headache, diarrhea, fatigue, muscle ache, chest pain, or taste dysfunction were also similar between the two groups. Palpitations were more common in patients with $\mathrm{f}$-QRS. There was only one difference in terms of comorbid conditions between the patients with fragmented and non-fragmented QRS. Renal failure was more common in patients with f-QRS. However, there was no statistical difference in hemodialysis. Other comorbid conditions were similar in both the groups. There was no significant difference in terms of CT thorax findings and length of in-hospital stay (days) in the 2 groups. The need for invasive mechanical ventilation $(63.6 \%$ vs. $41.5 \%, \mathrm{p}=0.003)$ and all-cause in-hospital mortality $[54.5 \%$ vs $28.9 \%$, log rank $\mathrm{p}=0.001$, relative risk $1.88,95 \%$ confidence interval (CI) 1.16-4.78] were significantly higher in patients with f-QRS (Fig. 2).

Laboratory parameters and medications are given in Table 2. Serum D-dimer, troponin I, and ferritin levels were statistically significantly higher in patients with f-QRS. However, serum albumin levels were significantly lower in the $\mathrm{f}$-QRS group. C-reactive protein (CRP) and CRP to albumin ratio (CAR) were higher in patients with severe COVID-19 and f-QRS. There was no significant difference between the two groups in other laboratory parameters. No statistically significant difference was found between the use of cardiovascular (antihypertensive, antihyperlipidemic, and antiaggregant) drugs in the groups. There was no difference in the use of hydroxychloroquine in patients with and without f-QRS. However, the use of azithromycin, favipiravir, and immunosuppressive agents or steroids was more common in patients with $\mathrm{f}-\mathrm{QRS}$.

ECG parameters are given in Table 3. The mean heart rate was significantly higher in patients with $f-Q R S$. The rates of atrial fibrillation, atrioventricular block, premature atrial contractions, premature ventricular contractions, right bundlebranch block, and left bundle-branch block were similar in both the groups. ST segment depression was higher in patients with $\mathrm{f}$-QRS. When we look at the localization of ST segment depression, it was found more in the anterior derivation. T-wave inversion was observed at a similar rate in both the groups as were $\mathrm{PR}$ and OT distance. ORS wave width was determined to be more in patients with $\mathrm{f}-\mathrm{QRS}$. When corrected $\mathrm{QT}$ (QTC) was calculated, it was found to be more in patients with f-QRS. Left

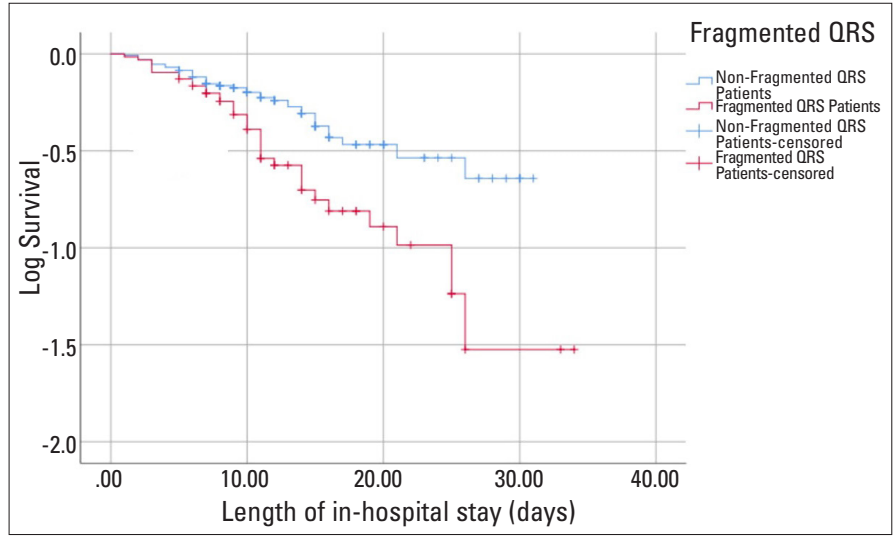

Figure 2. Kaplan-Meier survival rates for patients with and without fragmented QRS

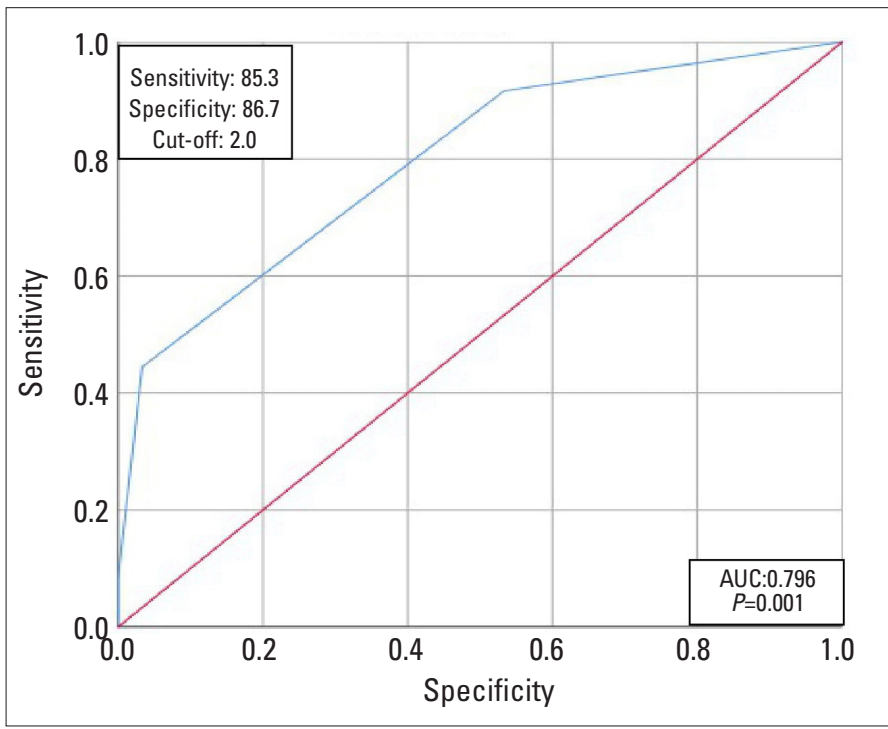

Figure 3. Receiver operating characteristic curve analysis for the number of leads with fragmented QRS to predict mortality

ventricular hypertrophy and right ventricular hypertrophy were similar in both the groups.

ROC analysis of the number of leads with $\mathrm{f}-\mathrm{QRS}$ to predict all-cause in-hospital mortality is shown in Figure 3. The ROC curve showed that the optimal cut-off value for the number of $f$ - $Q R S$ leads is $\geq 2$. A number value of $f-Q R S$ leads $\geq 2$ yields sensitivity and specificity (85.3\% and $86.7 \%$, respectively) for predicting in-hospital all-cause mortality.

$\mathrm{f}$-QRS locations were grouped as anterior, lateral, and inferior. $\mathrm{f}$-QRS was observed in 2 different regions in 17 patients. The effect of $\mathrm{f}-\mathrm{QRS}$ detection region on mortality was evaluated by logistic regression. $\mathrm{f}-\mathrm{QRS}$ increased mortality by 2.6 times when observed in lateral leads, 2.5 times when observed in inferior leads, and 3.7 times when observed in anterior leads (Table 4).

After adjustment for potential confounders, multivariable analyses showed that urea (OR: 1.030, 95\% Cl: 1.013-1.048, $\mathrm{p}=0.002$ ), CAR (OR: $1.238,95 \% \mathrm{Cl}: 1.011-1.421, \mathrm{p}=0.021$ ), D-dimer (OR:1.316, 95\% Cl:1.009-1.454, $\mathrm{p}=0.033$ ), age (OR: 1.064, 95\% Cl: 1.018-1.113, p=0.006), hypertension (OR: 3.507, 


\begin{tabular}{|c|c|c|c|}
\hline & $\begin{array}{c}\text { Patients with non-fragmented } \\
\text { ORS ( } n=135)\end{array}$ & $\begin{array}{l}\text { Patients with fragmented ORS } \\
\qquad(\mathrm{n}=66)\end{array}$ & $P$-value \\
\hline Age, years & $64.08 \pm 13.21$ & $66.29 \pm 13.72$ & 0.273 \\
\hline Female sex, n (\%) & $58(43.0)$ & $26(39.4)$ & 0.630 \\
\hline Smoking, n (\%) & $55(40.7)$ & $24(36.4)$ & 0.551 \\
\hline Alcohol use, n (\%) & $17(12.6)$ & $5(7.6)$ & 0.285 \\
\hline Body mass index, $\mathrm{kg} / \mathrm{m}^{2}$ & $26.26 \pm 3.40$ & $26.58 \pm 3.69$ & 0.543 \\
\hline Systolic blood pressure, $\mathrm{mm} \mathrm{Hg}$ & $137.53 \pm 24.60$ & $133.23 \pm 21.74$ & 0.229 \\
\hline Diastolic blood pressure, $\mathrm{mm} \mathrm{Hg}$ & $83.64 \pm 16.70$ & $80.47 \pm 15.46$ & 0.197 \\
\hline \multicolumn{4}{|l|}{ Symptoms at admission, $n(\%)$} \\
\hline Fever & $78(57.8)$ & $35(53.0)$ & 0.524 \\
\hline Cough & $43(31.9)$ & $22(33.3)$ & 0.833 \\
\hline Shortness of breath & $89(65.9)$ & $40(60.4)$ & 0.460 \\
\hline Headache & $2(1.5)$ & $1(1.5)$ & 0.212 \\
\hline Diarrhea & $6(4.4)$ & $1(1.5)$ & 0.287 \\
\hline Fatigue, tiredness & $14(10.4)$ & $7(10.6)$ & 0.959 \\
\hline Palpitation & 0 & $3(4.5)$ & 0.013 \\
\hline Muscle ache & $9(6.7)$ & $3(4.5)$ & 0.551 \\
\hline Sore throat & $5(3.7)$ & $6(9.1)$ & 0.115 \\
\hline Chest pain & $3(2.2)$ & $1(1.5)$ & 0.736 \\
\hline Taste dysfunction & $3(2.2)$ & $2(3.0)$ & 0.730 \\
\hline \multicolumn{4}{|l|}{ Comorbidities, n (\%) } \\
\hline Diabetes mellitus & $55(40.7)$ & $19(28.8)$ & 0.099 \\
\hline Hypertension & $84(62.2)$ & $35(53.0)$ & 0.213 \\
\hline Anemia & $27(20.0)$ & $15(22.7)$ & 0.655 \\
\hline Renal failure & $21(15.6)$ & $19(28.8)$ & 0.027 \\
\hline Dialysis & $7(5.2)$ & $7(10.6)$ & 0.156 \\
\hline $\mathrm{CAD}$ & $26(19.3)$ & $15(22.7)$ & 0.567 \\
\hline $\mathrm{PCl} / \mathrm{CABG}$ & $18(13.3)$ & $10(15.2)$ & 0.727 \\
\hline Peripheral vascular disease & $2(1.5)$ & $1(1.5)$ & 0.212 \\
\hline Chronic heart failure (HFrEF) & $10(7.4)$ & $6(9.1)$ & 0.679 \\
\hline Chronic obstructive pulmonary disease & $8(5.9)$ & $8(12.1)$ & 0.128 \\
\hline Hyperlipidemia & $21(15.6)$ & $9(13.6)$ & 0.720 \\
\hline Malignancy & $4(3.0)$ & $3(4.5)$ & 0.566 \\
\hline CVA/TIA & $8(5.9)$ & $7(10.6)$ & 0.236 \\
\hline \multicolumn{4}{|l|}{ Thorax CT findings, $\mathbf{n}(\%)$} \\
\hline No significant finding & $6(4.4)$ & $1(1.5)$ & 0.287 \\
\hline Ground glass opacity & $122(90.4)$ & $60(90.9)$ & 0.902 \\
\hline Pneumonic consolidation & $15(11.1)$ & $10(15.2)$ & 0.415 \\
\hline Pleural effusion & $13(9.6)$ & $7(10.6)$ & 0.828 \\
\hline Invasive mechanical ventilation, $\mathrm{n}(\%)$ & $56(41.5)$ & $42(63.6)$ & 0.003 \\
\hline Length of in-hospital stay (days) & $12.82 \pm 6.94$ & $12.70 \pm 7.49$ & 0.907 \\
\hline In-hospital mortality, n (\%) & $39(28.9)$ & $36(54.5)$ & 0.001 \\
\hline
\end{tabular}




\begin{tabular}{|c|c|c|c|}
\hline & $\begin{array}{l}\text { Patients with non-fragmented } \\
\text { QRS ( } n=135)\end{array}$ & $\begin{array}{l}\text { Patients with fragmented QRS } \\
\qquad(\mathrm{n}=66)\end{array}$ & $P$-value \\
\hline Urea, mg/dL & $49.00(35.00-69.50)$ & $54.50(40.25-84.50)$ & 0.132 \\
\hline Serum creatinine, $\mathrm{mg} / \mathrm{dL}$ & $0.87(0.71-1.25)$ & $1.05(0.70-1.61)$ & 0.193 \\
\hline Serum calcium, mg/dL & $8.31 \pm 0.69$ & $8.21 \pm 0.69$ & 0.317 \\
\hline Uric acid, mg/dL & $5.40(4.30-7.20)$ & $5.75(3.60-7.70)$ & 0.641 \\
\hline Albumin, $\mathrm{g} / \mathrm{dL}$ & $3.49 \pm 0.53$ & $3.31 \pm 0.62$ & 0.031 \\
\hline Aspartate transaminase, $\mathrm{u} / \mathrm{L}$ & $32.00(21.50-47.50)$ & $36.00(27.25-54.75)$ & 0.126 \\
\hline Ferritin $\mathrm{ng} / \mathrm{mL}$ & $352.40(157.25-731.45)$ & $688.55(340.30-1136.25)$ & 0.003 \\
\hline Hemoglobin, g/dL & $11.61 \pm 1.91$ & $11.62 \pm 2.21$ & 0.973 \\
\hline 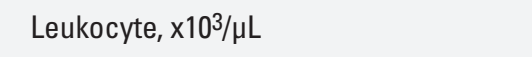 & $10851.85 \pm 5069.71$ & $11974.24 \pm 6711.99$ & 0.188 \\
\hline 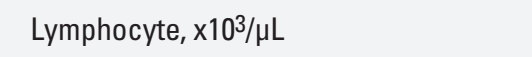 & $1177.78 \pm 642.78$ & $1126.82 \pm 785.67$ & 0.625 \\
\hline C-reactive protein, $\mathrm{mg} / \mathrm{dL}$ & $146.79 \pm 104.79$ & $175.94 \pm 94.41$ & 0.041 \\
\hline C-reactive protein/albumin ratio, $\mathrm{mg} / \mathrm{g}$ & $40.13 \pm 36.64$ & $56.93 \pm 35.91$ & 0.032 \\
\hline \multicolumn{4}{|l|}{ Medications, n (\%) } \\
\hline Acetylsalicylic acid & $51(37.8)$ & $31(47.0)$ & 0.213 \\
\hline Clopidogrel & $16(11.9)$ & 10 (15.2) & 0.513 \\
\hline Statin & $20(14.8)$ & $9(13.6)$ & 0.823 \\
\hline Hydroxychloroquine & $130(96.3)$ & $64(97.0)$ & 0.807 \\
\hline Azithromycin & $84(62.2)$ & $51(77.3)$ & 0.033 \\
\hline Favipiravir & $89(65.9)$ & $53(80.3)$ & 0.036 \\
\hline Immunosuppressive agent or steroid & $49(36.3)$ & $35(53.0)$ & 0.024 \\
\hline Vitamin B & $135(100)$ & $66(100)$ & - \\
\hline Vitamin C & $135(100)$ & $66(100)$ & - \\
\hline
\end{tabular}

95\% Cl: 1.206-10.194, $\mathrm{p}=0.021$ ), renal failure (OR: $6.611,95 \% \mathrm{Cl}$ : 1.152-37.941, $p=0.034$ ), troponin-I (OR: 1.493, 95\% Cl: 1.0541.853, $p=0.039$ ), and f-QRS (OR: 1.041, 95\% Cl: 1.021-1.192, $p=0.040$ ) were independently associated with in-hospital death Table 5).

There was a positive correlation between $\mathrm{f}-\mathrm{QRS}$ and CRP $(r=0.261 ; p=0.034)$ and CAR $(r=0.335 ; p=0.006)$. However, there was no correlation between $f-0 R S$ and $D$-dimer $(r=0.065$; $p=0.605)$, troponin $\mathrm{I}(r=0.136 ; p=0,277)$, and ferritin $(r=0.070$; $p=0,578)$. However, there was a negative correlation between the frequency of $f-Q R S$ and albumin ( $r=-0.385 ; p=0.001$ ) (Table 6).

When we compared the ECG parameters of the survivors and non-survivors, it was found that the prevalence of $f-0 R S$ was higher in non-survivors. There was no significant difference in PR and QRS durations. The mean QTc interval was longer in non-survivors. Heart rate was significantly higher in non-survivors. ST segment depression was observed more in non-survivors, and T-wave inversion was similar in both the groups (Fig. 4). 


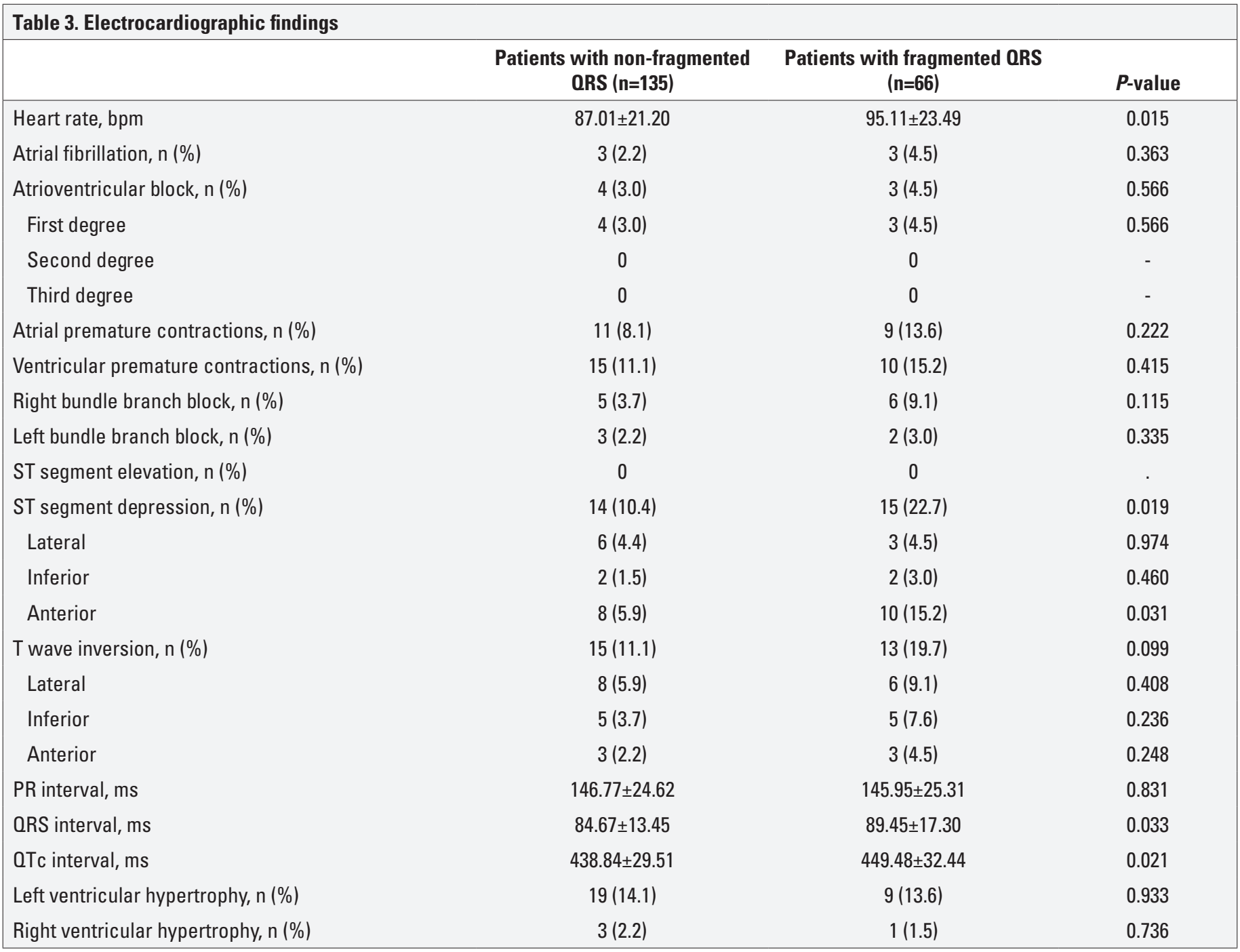

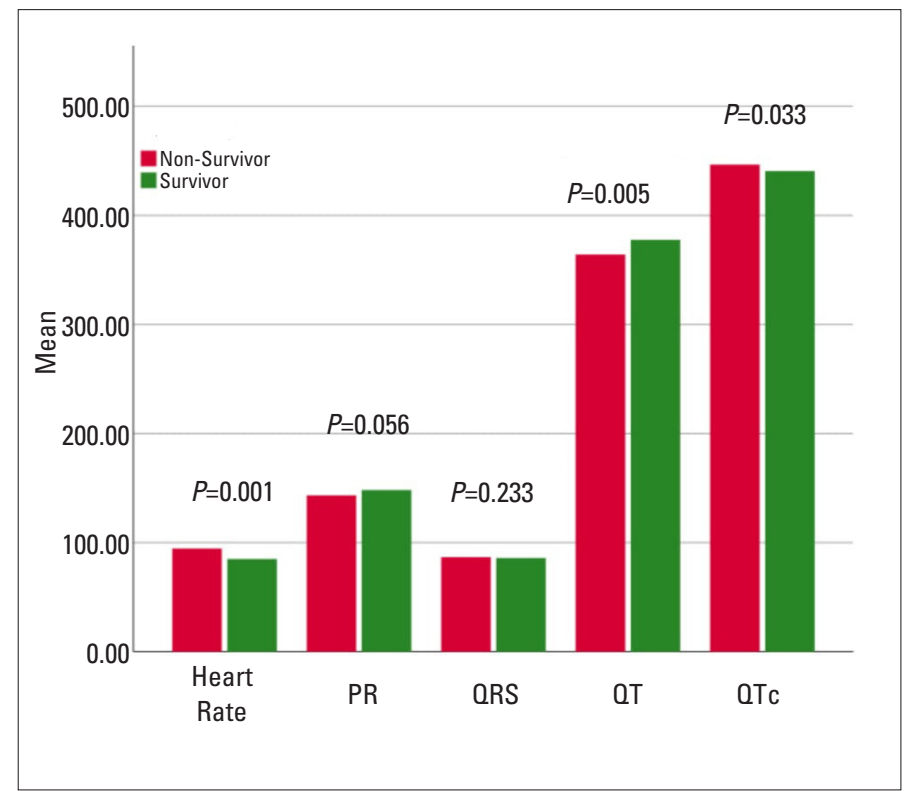

Figure 4. Comparison of ECG parameters in surviving and deceased patients
Higher serum urea, aspartate transaminase, alanine transaminase, D-dimer, troponin I, ferritin, CRP levels, and CAR were detected in non-survivors. There was no statistical difference between non-survivors and survivors in terms of the use of hydroxychloroquine, azithromycin, and favipiravir (Table 7).

First, we carried out a study of the reproducibility of the electrocardiographic data by analyzing interobserver and intraobserver variability. The ICC for intraobserver correlation was 0.988 (95\% Cl: $0.980-0.933)$ for the estimation of the $\mathrm{f}-\mathrm{QRS}$ number and was 0.973 ( $95 \% \mathrm{Cl}: 0.952-0.984)$ for the calculation of the $\mathrm{f}$-QRS when interobserver correlation was examined. These findings correspond to excellent interobserver and intraobserver correlations. There was also excellent reproducibility in the detection of QRS fragmentation for intraobserver (Kappa: 1.0) and interobserver (Kappa: 0.960) agreement.

\section{Discussion}

In this study, we investigated whether the presence of $\mathrm{f}$-QRS on ECG is a predictor for all-cause mortality in patients 


\begin{tabular}{|c|c|c|c|c|}
\hline & OR & $\begin{array}{l}95 \% \mathrm{CI} \\
\text { lower }\end{array}$ & $\begin{array}{l}95 \% \text { CI } \\
\text { upper }\end{array}$ & $\boldsymbol{P}$-value \\
\hline $\begin{array}{l}\text { Fragmented QRS lateral } \\
\text { leads }(n=20)\end{array}$ & 2.641 & 1.090 & 7.499 & 0.022 \\
\hline $\begin{array}{l}\text { Fragmented QRS inferior } \\
\text { leads }(n=29)\end{array}$ & 2.540 & 1.108 & 5.822 & 0.028 \\
\hline $\begin{array}{l}\text { Fragmented QRS } \\
\text { anterior leads }(n=34)\end{array}$ & 3.785 & 1.657 & 8.648 & 0.002 \\
\hline \multicolumn{5}{|c|}{$\mathrm{Cl}$ - confidence interval; OR - odds ratio } \\
\hline
\end{tabular}

\begin{tabular}{|c|c|c|c|c|}
\hline & OR & $\begin{array}{l}95 \% \mathrm{Cl} \\
\text { Lower }\end{array}$ & $\begin{array}{l}95 \% \text { CI } \\
\text { Upper }\end{array}$ & $P$-value \\
\hline Age & 1.064 & 1.018 & 1.113 & 0.006 \\
\hline Hypertension & 3.507 & 1.206 & 10.194 & 0.021 \\
\hline Renal failure & 6.611 & 1.152 & 37.941 & 0.034 \\
\hline Troponin-I & 1.493 & 1.054 & 1.853 & 0.039 \\
\hline $\begin{array}{l}\text { C-reactive protein/ } \\
\text { albumin ratio }\end{array}$ & 1.238 & 1.011 & 1.421 & 0.021 \\
\hline D-dimer & 1.316 & 1.009 & 1.454 & 0.033 \\
\hline Urea & 1.030 & 1.013 & 1.048 & 0.002 \\
\hline$f-Q R S$ & 1.041 & 1.021 & 1.192 & 0.040 \\
\hline
\end{tabular}

\begin{tabular}{|c|c|c|}
\hline \multicolumn{3}{|c|}{$\begin{array}{l}\text { Table 6. Correlation analyses between fORS and laboratory } \\
\text { parameters in patients with COVID-19 }\end{array}$} \\
\hline Laboratory parameters & r value & $\boldsymbol{P}$-value \\
\hline Serum creatinine, $\mathrm{mg} / \mathrm{dL}$ & 0.231 & 0.063 \\
\hline Serum calcium, mg/dL & -0.071 & 0.572 \\
\hline D-dimer, ng/mL & 0.065 & 0.605 \\
\hline Troponin, ng/mL & 0.136 & 0.277 \\
\hline Ferritin ng/mL & 0.070 & 0.578 \\
\hline C-reactive protein, $\mathrm{mg} / \mathrm{dL}$ & 0.261 & 0.034 \\
\hline C-reactive protein / albumin ratio, $\mathrm{mg} / \mathrm{g}$ & 0.335 & 0.006 \\
\hline Albumin, g/dL & -0.385 & 0.001 \\
\hline
\end{tabular}

in the ICU with COVID-19. Our study has several important findings. First, all-cause in-hospital mortality was significantly higher in patients with f-QRS. Second, serum CRP, D-dimer, troponin I, ferritin levels, and CAR are significantly higher in these patients. Third, there is a positive correlation between the presence of $f-Q R S$ with CRP and CAR. Serum albumin level is lower in patients with $\mathrm{f}$-QRS. Considering these data, we believe that inflammation is more in $\mathrm{s}$ patients with severe COVID-19 and f-QRS. Finally, the presence of $\mathrm{f}-\mathrm{QRS}$ in critically ill patients with COVID-19 is independently associated with inhospital death.
The impact of the COVID-19 pandemic continues around the world. The most common indication requiring follow-up in ICU is respiratory failure because of pulmonary involvement. Acute respiratory distress syndrome caused by pulmonary involvement is the most common cause of death from COVID-19 (12). Patients with COVID-19 with cardiovascular comorbidities tend to have higher disease severity and case fatality rates $(13,14)$. It is not known how underlying cardiovascular disease (CVD) contributes to the severity of COVID-19 disease. However, it is thought that hyperinflammation plays a role in this. As the immune system encounters the virus and gets to know its antigens, it produces large amounts of proinflammatory cytokines and chemokines. In some patients, this activation becomes so great that a cytokine storm develops, resulting in thrombotic propensity and multi-organ failure, and eventually death $(15,16)$. High levels of biomarkers can be observed in patients with severe COVID-19 because of increased inflammation. CRP, D-dimer, ferritin, albumin, and troponin I are some of these biomarkers and are helpful parameters to the clinician in risk stratification of patients with severe COVID-19 (17-22). In addition, many studies have shown that CAR is a valuable prognostic factor to detect the inflammatory state in different inflammatory diseases (23). In our study, high CRP, D-dimer, CAR, troponin I, and low albumin levels were detected in patients with severe COVID-19. Importantly, the prevalence of $\mathrm{f}-\mathrm{QRS}$ was higher in these patients. These data suggest that there may be an association between $\mathrm{f}-\mathrm{QRS}$ and inflammation.

Myocardial cells are a potential target of SARS-CoV-2 (24). In addition, fulminant myocarditis because of inflammatory mononuclear infiltration in myocardial tissue under high viral load has been described $(25,26)$. Endothelial cell infection has been reported in many organs, including the heart vessels, and another possible mechanism of myocardial lesion and troponin elevation has been mentioned (27). Increasing inflammation caused by COVID-19 causes myocardial injury. The incidence of severe ventricular dysfunction and cardiac arrhythmia owing to this injury is increasing. Myocardial injury is a common complication in hospitalized patients with or without pre-existing CVD and is associated with in-hospital mortality and a poor prognosis (28). Compared with non-ICU admissions, there was a larger proportion of arrhythmias found in ICU admissions in 2 studies $(1.2 \%$ $16.7 \%$ and $40 \%-44 \%$, respectively) $(29,30)$. The mean OTC interval was longer in the $\mathrm{f}-\mathrm{QRS}$ group in our study. However, the rate of favipiravir and azithromycin use was also higher in the same group. Therefore, in patients with $\mathrm{f}-\mathrm{QRS}$, the difference in QT interval and its predictive value for adverse arrhythmic events can be considered in patients with or without any drugs that prolong OT intervals. However, the mean OTc interval was longer in non-survivors. Prolonged QTc may be contributing to increased malignant arrhythmias in patients with severe COVID19. OT prolonging drugs should be used more carefully in patients with severe COVID-19.

$\mathrm{f}-\mathrm{QRS}$ is an ECG finding reflecting impaired ventricular depolarization owing to heterogeneous electrical activation of the injured myocardium. $\mathrm{f}-\mathrm{QRS}$ is recognized as a new and useful 


\begin{tabular}{|c|c|c|c|}
\hline & Survivor ( $n=126$ ) & Non-survivor $(n=75)$ & $P$-value \\
\hline Number of $f$-QRS leads, $n$ & $1.57 \pm 0.57$ & $2.44 \pm 0.77$ & 0.001 \\
\hline PR interval, ms & $148.22 \pm 23.08$ & $143.36 \pm 27.52$ & 0.056 \\
\hline QRS interval, ms & $85.90 \pm 15.51$ & $86.80 \pm 14.03$ & 0.223 \\
\hline ST segment depression, $n(\%)$ & $8(6.3)$ & $21(28)$ & 0.001 \\
\hline T wave inversion, $\mathrm{n}(\%)$ & $13(10.3)$ & $15(20)$ & 0.055 \\
\hline Urea, mg/dl & $45.50(33.00-60.75)$ & $60.00(46.50-102.00)$ & 0.001 \\
\hline Serum creatinine, $\mathrm{mg} / \mathrm{dL}$ & $0.87(0.71-1.30)$ & $1.04(0.73-1.50)$ & 0.134 \\
\hline D-dimer, ng/mL & $432.50(253.75-795.50)$ & $1098.00(535.50-2426.00)$ & 0.001 \\
\hline Troponin I, ng/mL & $0.006(0.002-0.013)$ & $0.078(0.011-0.227)$ & 0.001 \\
\hline Ferritin $\mathrm{ng} / \mathrm{mL}$ & $330.75(126.20-739.90)$ & $613.10(348.30-1093.40)$ & 0.001 \\
\hline C-reactive protein, $\mathrm{mg} / \mathrm{dL}$ & $146.33 \pm 85.29$ & $227.20 \pm 106.18$ & 0.001 \\
\hline C-reactive protein/albumin ratio, $\mathrm{mg} / \mathrm{g}$ & $41.88 \pm 25.41$ & $75.38 \pm 42.06$ & 0.001 \\
\hline Hydroxychloroquine, n (\%) & $120(95.2)$ & $74(98.7)$ & 0.200 \\
\hline Azithromycin, n (\%) & $86(68.2)$ & $49(65.3)$ & 0.334 \\
\hline Favipiravir, n (\%) & $87(69.0)$ & $55(73.3)$ & 0.519 \\
\hline
\end{tabular}

marker of myocardial scar or fibrosis (31). 0 wave and f-QRS were compared in terms of myocardial scar in patients who underwent nuclear stress test, and specificity of f-QRS was found to be superior to 0 wave (7). In patients with left ventricular dysfunction, the presence of myocardial fibrosis may cause ventricular arrhythmias. Cardiac MRI studies in patients with ischemic and non-ischemic cardiomyopathy have shown that myocardial fibrosis represents an arrhythmogenic substrate (32, 33). Imaging methods used in the detection of myocardial fibrosis are more expensive and complex than $\mathrm{f}-\mathrm{QRS}$, which is easily detected on an ECG device. In a study, the rate of detection of $\mathrm{f}$-QRS in patients with COVID-19 was calculated as $24.2 \%$ (34). Only patients with severe COVID-19 disease who were followed up in the ICU were included in our study, and the $\mathrm{f}$-QRS rate was calculated as $32.84 \%$. We observed that patients with $\mathrm{f}$-QRS included in our study needed more mechanical ventilation and that mortality was higher in these patients. The mean heart rate and symptom of palpitation were found to be higher in the ECG in patients with $\mathrm{f}-\mathrm{QRS}$. At the same time, more ST depression was observed in this group. ST segment depression is a sign of myocardial ischemia and has been associated with increased mortality in COVID-19 $(35,36)$. Sinus tachycardia may indicate increased myocardial oxygen demand (37). In a study of patients with COVID-19, ST-T segment abnormal change rate and sinus tachycardia were observed to correlate with disease severity. ST-T segment changes and sinus tachycardia increased as the disease severity increased (38). ST-T segment change and sinus tachycardia may be related to myocardial damage caused by SARS-CoV-2.

Especially in patients with COVID-19, f-ORS may be a predictor of poor clinical outcomes. In a recently published paper, Yildirim et al. (39) studied 114 patients with COVID-19. In this study, similar to our results, hospitalization duration, ICU requirement, all-cause mortality, and cardiac mortality were found to be higher in patients with COVID-19 with f-QRS. However, this study revealed that there was a positive relationship between QRS duration and duration of hospital stay, need for ICU, and mortality, but there was no relationship between $\mathrm{T}$ inversion and mortality (39). In contrast, no relationship was found between QRS duration and mortality in our study. However, there was a significant difference in the QRS duration of patients with and without f-QRS. In another retrospective study, Bektas et al. (34) suggested that presence of $\mathrm{f}-\mathrm{QRS}$ in patients with COVID-19 may be useful in predicting cardiovascular outcomes. Similarly, Barman et al. (40) found that the presence of $\mathrm{f}-\mathrm{QRS}$ in patients with SARS-CoV-2 infection was independently associated with ICU admission.

Fragmentation in ECG is a predictor of QTc prolongation (41). Prolongation of the electrocardiographic $\mathrm{QT}$ interval is an established risk factor for torsades de pointes (42). OT prolonging drugs such as hydroxychloroquine and azithromycin can be used in the treatment of patients with COVID-19 (43). Therefore, fragmentation in ECG may contribute arrhythmic events. 
In a study, the presence of $3 \mathrm{f}-\mathrm{QRS}$ leads was identified as an independent predictor of cardiac death or hospitalization for heart failure in patients with prior myocardial infarction (44). In another study, f-QRS in anterior leads was found to be associated with higher GRACE risk score and Killip class (45). In our study, the lead with $\mathrm{f}-\mathrm{QRS}$ cut-off value was found to be $\geq 2$. A significant increase in mortality was observed with $\mathrm{f}$-QRS seen in at least 2 different derivations. The association of $f-Q R S$ with mortality in the anterior derivations was more determined than the inferior and lateral leads.

\section{Study limitations}

Our study had several limitations. Its retrospective nature and relatively small patient population are major limitations. $\mathrm{f}-\mathrm{QRS}$ can be seen in cardiovascular diseases such as coronary artery disease, atrial fibrillation, and heart failure. We did not have ECG data of the patients before the hospitalization. In addition, it is not clear whether $\mathrm{f}$-QRS develops because of COVID-19 as serial ECG follow-up was not performed after hospitalization. Lack of echocardiographic data can be considered as a limitation of our study.

\section{Conclusion}

The presence of $\mathrm{f}-\mathrm{QRS}$ in ECG is associated with higher inhospital all-cause mortality in patients with severe COVID-19. Furthermore, $\mathrm{f}-\mathrm{QRS}$ is positively correlated with serum CRP level and CAR and negatively correlated with serum albumin, which are indicators of inflammation. The prevalence of prolonged QTC is higher in patients with $\mathrm{f}-\mathrm{QRS}$. Therefore, during the pandemic period where the number of patients increases every day, the presence of $f-Q R S$ in ECG, which is an inexpensive and easily accessible marker, can be used to determine the mortality risk of critically ill patients with COVID-19.

\section{Conflict of interest: None declared.}

Peer-review: Externally peer-reviewed.

Author contributions: Concept - I.H.Ö.; Design - I.H.Ö.; Supervision - H.T.; Fundings - I.H.Ö., B.Ö., M.B.Ö., R.G., N.Ç., E.Ö., B.S.Y., H.T.; Materials - I.H.Ö., B.Ö., M.B.Ö., R.G., N.Ç., E.Ö., B.S.Y., H.T.; Data collection \&/or processing - I.H.Ö., B.Ö., M.B.Ö., R.G.; Analysis \&/or interpretation - B.Ö., N.C..; Literature search - B.Ö., M.B.Ö., R.G., N.Ç., B.S.Y.; Writing - I.H.Ö., N.Ç.; Critical review H.T.

\section{References}

1. Zhou P, Yang XL, Wang XG, Hu B, Zhang L, Zhang W, et al. A pneumonia outbreak associated with a new coronavirus of probable bat origin. Nature 2020; 579: 270-3. [Crossref]

2. Gorbalenya AE, Baker SC, Baric R, Groot RJd, Drosten C, Gulyaeva $A A$, et al.; Coronaviridae Study Group of the International Committee on Taxonomy of Viruses. The species Severe acute respiratory syndrome-related coronavirus: classifying 2019-nCoV and naming it SARS-CoV-2. Nat Microbiol 2020; 5: 536-44. [Crossref]
3. Driggin E, Madhavan MV, Bikdeli B, Chuich T, Laracy J, BiondiZoccai G, et al. Cardiovascular Considerations for Patients, Health Care Workers, and Health Systems During the COVID-19 Pandemic. J Am Coll Cardiol 2020; 75: 2352-71. [Crossref]

4. Madjid M, Safavi-Naeini P, Solomon SD, Vardeny O. Potential Effects of Coronaviruses on the Cardiovascular System: A Review. JAMA Cardiol 2020; 5: 831-40. [Crossref]

5. Lanza GA, De Vita A, Ravenna SE, D'Aiello A, Covino M, Franceschi $F$, et al. Electrocardiographic findings at presentation and clinical outcome in patients with SARS-CoV-2 infection. Europace 2021; 23 : 123-9. [Crossref]

6. Basaran Y, Tigen K, Karaahmet T, Isiklar I, Cevik C, Gurel E, et al. Fragmented QRS complexes are associated with cardiac fibrosis and significant intraventricular systolic dyssynchrony in nonischemic dilated cardiomyopathy patients with a narrow QRS interval. Echocardiography 2011; 28: 62-8. [Crossref]

7. Das MK, Khan B, Jacob S, Kumar A, Mahenthiran J. Significance of a fragmented QRS complex versus a 0 wave in patients with coronary artery disease. Circulation 2006; 113: 2495-501. [Crossref]

8. Das MK, Maskoun W, Shen C, Michael MA, Suradi H, Desai M, et al. Fragmented QRS on twelve-lead electrocardiogram predicts arrhythmic events in patients with ischemic and nonischemic cardiomyopathy. Heart Rhythm 2010; 7: 74-80. [Crossref]

9. Sha J, Zhang S, Tang M, Chen K, Zhao X, Wang F. Fragmented QRS is associated with all-cause mortality and ventricular arrhythmias in patient with idiopathic dilated cardiomyopathy. Ann Noninvasive Electrocardiol 2011; 16: 270-5. [Crossref]

10. Jain R, Singh R, Yamini S, Das MK. Fragmented ECG as a risk marker in cardiovascular diseases. Curr Cardiol Rev 2014; 10: 277-86. [Crossref]

11. Supreeth RN, Francis J. Fragmented QRS - Its significance. Indian Pacing Electrophysiol J 2020; 20: 27-32. [Crossref]

12. Li X, Ma X. Acute respiratory failure in COVID-19: is it "typical" ARDS? Crit Care 2020; 24: 198. [Crossref]

13. Li B, Yang J, Zhao F, Zhi L, Wang X, Liu L, et al. Prevalence and impact of cardiovascular metabolic diseases on COVID-19 in China. Clin Res Cardiol 2020; 109: 531-8. [Crossref]

14. Yang J, Zheng Y, Gou X, Pu K, Chen Z, Guo Q, et al. Prevalence of comorbidities and its effects in patients infected with SARS-CoV-2: a systematic review and meta-analysis. Int J Infect Dis 2020; 94: 91-5. [Crossref]

15. Sarzi-Puttini P, Giorgi V, Sirotti S, Marotto D, Ardizzone S, Rizzardini G, et al. COVID-19, cytokines and immunosuppression: what can we learn from severe acute respiratory syndrome? Clin Exp Rheumatol 2020; 38: 337-42.

16. Li X, Geng M, Peng Y, Meng L, Lu S. Molecular immune pathogenesis and diagnosis of COVID-19. J Pharm Anal 2020; 10: 102-8. [Crossref]

17. Huang I, Pranata R, Lim MA, Oehadian A, Alisjahbana B. C-reactive protein, procalcitonin, D-dimer, and ferritin in severe coronavirus disease-2019: a meta-analysis. Ther Adv Respir Dis 2020; 14: 1753466620937175. [Crossref]

18. Wang Y, Shu H, Liu H, Li X, Zhou X, Zou X, et al. The peak levels of highly sensitive troponin I predicts in-hospital mortality in COVID19 patients with cardiac injury: a retrospective study. Eur Heart $\mathrm{J}$ Acute Cardiovasc Care 2021; 10: 6-15. [Crossref]

19. Li Y, Zhao K, Wei H, Chen W, Wang W, Jia L, et al. Dynamic relationship between D-dimer and COVID-19 severity. Br J Haematol 2020; 190: e24-7. [Crossref]

20. Zhou C, Chen Y, Ji Y, He X, Xue D. Increased Serum Levels of Hepcidin and Ferritin Are Associated with Severity of COVID-19. Med Sci Monit 2020; 26: e926178. [Crossref] 
21. Violi F, Cangemi R, Romiti GF, Ceccarelli G, Oliva A, Alessandri F, et al. Is Albumin Predictor of Mortality in COVID-19? Antioxid Redox Signal 2021; 35: 139-42. [Crossref]

22. Sahu BR, Kampa RK, Padhi A, Panda AK. C-reactive protein: A promising biomarker for poor prognosis in COVID-19 infection. Clin Chim Acta 2020; 509: 91-4. [Crossref]

23. Fairclough E, Cairns E, Hamilton J, Kelly C. Evaluation of a modified early warning system for acute medical admissions and comparison with C-reactive protein/albumin ratio as a predictor of patient outcome. Clin Med (Lond) 2009; 9: 30-3. [Crossref]

24. Ruan Q, Yang K, Wang W, Jiang L, Song J. Clinical predictors of mortality due to COVID-19 based on an analysis of data of 150 patients from Wuhan, China. Intensive Care Med 2020; 46: 846-8. [Crossref]

25. Sala S, Peretto G, Gramegna M, Palmisano A, Villatore A, Vignale $D$, et al. Acute myocarditis presenting as a reverse Tako-Tsubo syndrome in a patient with SARS-CoV-2 respiratory infection. Eur Heart J 2020; 41: 1861-2. [Crossref]

26. Chen C, Zhou Y, Wang DW. SARS-CoV-2: a potential novel etiology of fulminant myocarditis. Herz 2020; 45:230-2. [Crossref]

27. Varga Z, Flammer AJ, Steiger $P$, Haberecker $M$, Andermatt R, Zinkernagel AS, et al. Endothelial cell infection and endotheliitis in COVID-19. Lancet 2020; 395: 1417-8. [Crossref]

28. Azevedo RB, Botelho BG, Hollanda JVG, Ferreira LVL, Junqueira de Andrade LZ, Oei SSML, et al. Covid-19 and the cardiovascular system: a comprehensive review. J Hum Hypertens 2021; 35: 4-11. [Crossref]

29. Wang D, Hu B, Hu C, Zhu F, Liu X, Zhang J, et al. Clinical Characteristics of 138 Hospitalized Patients With 2019 Novel Coronavirus-Infected Pneumonia in Wuhan, China. JAMA 2020; 323: 1061-9. [Crossref]

30. Zhang G, Hu C, Luo L, Fang F, Chen Y, Li J, et al. Clinical features and short-term outcomes of 221 patients with COVID-19 in Wuhan, China. J Clin Virol 2020; 127: 104364. [Crossref]

31. Mittal SR. Fragmented QRS: A simple electrocardiographic prognostic marker in cardiovascular disease. J Clin Prev Cardiol 2016; 5: 94-8. [Crossref]

32. Bello D, Fieno DS, Kim RJ, Pereles FS, Passman R, Song G, et al. Infarct morphology identifies patients with substrate for sustained ventricular tachycardia. J Am Coll Cardiol 2005; 45: 1104-8. [Crossref]

33. Assomull RG, Prasad SK, Lyne J, Smith G, Burman ED, Khan M, et al. Cardiovascular magnetic resonance, fibrosis, and prognosis in dilated cardiomyopathy. J Am Coll Cardiol 2006; 48: 1977-85. [Crossref]

34. Bektaş O, Çerik IB, Çerik HÖ, Karagöz A, Kaya Y, Dereli S, et al. The relationship between severe acute respiratory syndrome coronavirus 2 (SARS - COV - 2) pandemic and fragmented ORS. J Electrocardiol 2020; 62: 10-3. [Crossref]

35. Wagner GS, Macfarlane P, Wellens $H$, Josephson M, Gorgels A, Mirvis DM, et al.; American Heart Association Electrocardiography and Arrhythmias Committee, Council on Clinical Cardiology;
American College of Cardiology Foundation; Heart Rhythm Society. AHA/ACCF/HRS recommendations for the standardization and interpretation of the electrocardiogram: part VI: acute ischemia/ infarction: a scientific statement from the American Heart Association Electrocardiography and Arrhythmias Committee, Council on Clinical Cardiology; the American College of Cardiology Foundation; and the Heart Rhythm Society. Endorsed by the International Society for Computerized Electrocardiology. J Am Coll Cardiol 2009; 53: 1003-11.

36. Denegri A, Pezzuto G, D'Arienzo M, Morelli M, Savorani F, Cappello CG, et al. Clinical and electrocardiographic characteristics at admission of COVID-19/SARS-CoV2 pneumonia infection. Intern Emerg Med 2021; 16: 1451-6. [Crossref]

37. Maroko PR, Kjekshus JK, Sobel BE, Watanabe T, Covell JW, Ross $\mathrm{J} J \mathrm{r}$, et al. Factors influencing infarct size following experimental coronary artery occlusions. Circulation 1971; 43: 67-82. [Crossref]

38. Wang Y, Chen L, Wang J, He X, Huang F, Chen J, et al. Electrocardiogram analysis of patients with different types of COVID-19. Ann Noninvasive Electrocardiol 2020; 25: e12806. [Crossref]

39. Yildirim A, Karaca IO, Yilmaz FK, Gunes HM, Cakal B. Fragmented QRS on surface electrocardiography as a predictor of cardiac mortality in patients with SARS-CoV-2 infection. J Electrocardiol 2021; 66: 108-12. [Crossref]

40. Barman HA, Atici A, Alici G, Sit O, Tugrul S, Gungor B, et al. The effect of the severity COVID-19 infection on electrocardiography. Am J Emerg Med 2021; 46: 317-22. [Crossref]

41. Aquino NJ, Centurión OA, Torales JM, Miño LM, Scavenius KE, Alderete JF, et al. Association of QRS Complex Fragmentation with QT Interval Prolongation in Patients with Ischemic Heart Disease. Curr Health Sci J 2019; 45: 398-404.

42. Malik M, Camm AJ. Evaluation of drug-induced QT interval prolongation: implications for drug approval and labelling. Drug Saf 2001; 24: 323-51. [Crossref]

43. Özdemir IH, Özlek B, Özen MB, Gündüz R, Çetin N, Bilge AR. Hydroxychloroquine/azithromycin treatment, $\mathrm{OT}$ interval and ventricular arrhythmias in hospitalised patients with COVID-19. Int J Clin Pract 2021; 75: e13896. [Crossref]

44. Torigoe K, Tamura A, Kawano Y, Shinozaki K, Kotoku M, Kadota J. The number of leads with fragmented QRS is independently associated with cardiac death or hospitalization for heart failure in patients with prior myocardial infarction. J Cardiol 2012; 59: 36-41. [Crossref]

45. Younis AS, El-Halag MI, ElBadry MA, Abbas NIM. Fragmented QRS complex frequency and location as predictor of cardiogenic shock and mortality following acute coronary syndrome. Egypt Heart $J$ 2020; 72: 43. [Crossref] 